\title{
Effects of different heat sources on the behaviour of blue tree monitors (Varanus macraei) in captivity
}

\author{
OLIVER THOMAS ${ }^{1}$, DANIEL KANE ${ }^{2} \&$ CHRISTOPHER J. MICHAELS ${ }^{2}$ \\ ${ }^{1} 10$ Harestone Hill, Caterham, Surrey, UK \\ ${ }^{2}$ Herpetology Section, Zoological Society of London, Regent's Park, London, NW1 4RY, UK \\ ${ }^{*}$ Corresponding author e-mail: olliethomas444@gmail.com
}

\section{INTRODUCTION}

Captiou aptive reptiles are typically maintained using artificial heat sources. If reptiles are to achieve their optimal thermal working temperatures, and exhibit natural behaviours and physiologies then artificial heat sources should replicate sunlight as closely as possible and provide basking zones that are large enough to suit their needs (Autumn \& De Nardo, 1995; Beaupre \& Zaidan, 2012; Michaels et al., 2014). A wide variety of heaters are commercially available that provide combined electromagnetic radiation that approximate to the biologically relevant components of sunlight (Baines et al., 2016).

Self-ballasted mercury vapour lamps are typically used for heating in captivity and emit a mixture of ultraviolet-A (UV-A) and $-B$ (UV-B) as well as visible light and infrared-A (IR-A).

Ultraviolet light is used by reptiles in a variety of ways such as recognition of conspecifics and food and the production of vitamin $D_{3}$ (Baines et al., 2016). A new development, an infrared lamp marketed as an 'Arcadia Deep Heat Projector' (Monkfield Nutrition Limited, Mepal, Cambridgeshire, UK), emits high levels of the medium wavelength infrared-B radiation (IR-B), a small amount of IR-A, very little visible light and no UV (Arcadia pers. Comms; information on packaging). This heat source is potentially much more energy efficient than mercury vapour lamps and so may represent a more economical approach to heating captive reptiles. Consequently, we compared the Arcadia Deep Heat Projector with mercury vapour lamps by recording the behaviour of captive blue tree monitors (Varanus macraei) when provided with these heat sources in succession.

\section{MATERIALS AND METHODS}

The study was undertaken at the Zoological Society of London using a male and a female blue tree monitor (Varanus macraei), both of which were 7.5 years (male) and 6 years (female) old at the time of study. An ethical review of the project was deemed unnecessary since it fell within the normal bounds of varanid husbandry and the project was approved on this basis (internally registered as ZDZ105). The lizards were housed in a concrete, mesh and glass enclosure (measuring $220 \times 160 \times$ $170 \mathrm{~cm}, \mathrm{~L} \times \mathrm{W} \times \mathrm{H}$ ) furnished with a variety of décor, including natural branches, hides, a painted concrete tree trunk, rock platforms, and a small water feature (Fig. 1). The substrate was a mixture of organic matter including peat-free compost and leaf litter. The ambient temperature in the enclosure was 26$30{ }^{\circ} \mathrm{C}$ in the day and $22-24{ }^{\circ} \mathrm{C}$ at night, which aligns with best practice husbandry for the species (Ziegler et al., 2009). The lizards' diet comprised of commercial feeder invertebrates and occasional defrosted vertebrates (mice, chicks etc.).

To record lizard behaviour, a time-lapse video camera (Plotwatcher Pro, Day6 Outdoors, USA) was installed in the front corner (from the public side) of the enclosure and set to take a photograph every 30 seconds. The camera was light activated and, as natural light penetrated the enclosure, it turned itself on roughly one hour before the enclosure lighting/heating came on, and off roughly one hour after it was switched off. The camera was left recording for eleven days, starting with a one day period for camera habituation for each treatment, hence yielding ten days of data. The first series of data were collected with two mercury vapour lamps (300W UltraVitalux, Osram, Germany) in place. The basking zone temperatures were $40-45{ }^{\circ} \mathrm{C}$ with a UV index of 3-6. This process was repeated when the heating system was changed to three IR lamps (Arcadia 50W 'Deep Heat Projectors', Monkfield Nutrition, UK). Under these lamps the basking zone temperatures were $39-43{ }^{\circ} \mathrm{C}$ with a UV index of 1.5-2. Lighting above the basking zone was provided by four fluorescent tubes (2x Arcadia $14 \%$ T5 tubes and 2x 'ProLite' T5 tubes, both $550 \mathrm{~mm}$ ) that gave ultraviolet B (UV-B) and small amounts of ultraviolet A (UV-A) throughout the study, set to a 12:12 photoperiod.

Surface temperatures were measured with a noncontact infrared thermometer (ZANMAX GM320, USA). We ensured that the expanse of the basking zones were identical (measuring $20 \times 75 \mathrm{~cm}$ ) between the two treatments. Filming of the lizards was then interrupted after the IR treatment and the IR lamps were replaced once again with mercury vapour lamps. After 14 days, filming was resumed to establish whether the lizards returned to a similar baseline pattern of behaviours.

Time-lapse videos were viewed using GameFinder Module software (V. 1.7.2, Day6 Outdoors, USA) which allows frame by frame playback. Data were entered into Microsoft Excel. An ethogram of relevant behaviours was created before the study through $3 \mathrm{~h}$ of lizard observation. The behaviours recorded were 'basking', 'resting', 'locomoting', 'out of sight' 
and 'other'. From the time lapse video, a 30 minute period of lizard behaviour was sampled in the morning (09:30-10:00 h), midday (13:00-13:30 h) and afternoon (17:30-18:00 h) of each of the ten sample days, resulting in 30 observation windows per treatment. The two individuals could be distinguished easily based on colour markings (Ziegler et al., 2009), size and other anatomical details. The lizards' behaviour and location within the enclosure were recorded for each of the 30 second intervals in the 30-minute sample period, giving 61 individual records (including time zero) per sample window, per lizard. If a keeper entered the enclosure during one of these sample windows, the sample window analysed on that occasion was shifted forwards or backwards by 30 minutes to control for human disturbance to the lizards' behaviour.

The data were analysed for normality and homoscedascity in $\mathrm{R}$ (v.3.5.2; R Core team 2018) but the assumptions required for the use of ANOVA were not met. Consequently, data were analysed by Friedman tests for repeated measures using an online calculator (Social Science Statistics 2019).

\section{RESULTS AND DISCUSSION}

The lizards exhibited basking, resting and locomoting behaviours under both heating array treatments. In the male lizard, when the heating was changed from mercury vapour to IR lamps there was a large increase in the average count of basking behaviour (Fig. 2) which was statistically significant $\left(\chi^{2}\right.$ $=12.200, P=0.002)$. This was associated with a statistically significant reduction in resting behaviour $\left(\chi^{2}=18.617, \mathrm{P}<\right.$ 0.001 ) but there was no change in the locomotory behaviours $\left(X^{2}=1.718, P=0.42\right)$. Similarly for the female, there was a large increase in basking behaviour (Fig. 2), although this was not actually statistically significant $\left(\chi^{2}=2.450 P=0.294\right)$, an associated significant reduction in resting behaviour $\left(\chi^{2}=\right.$ $7.267, P=0.026)$, and again no change observed in locomotory behaviours $\left(X^{2}=0.350, P=0.839\right)$.

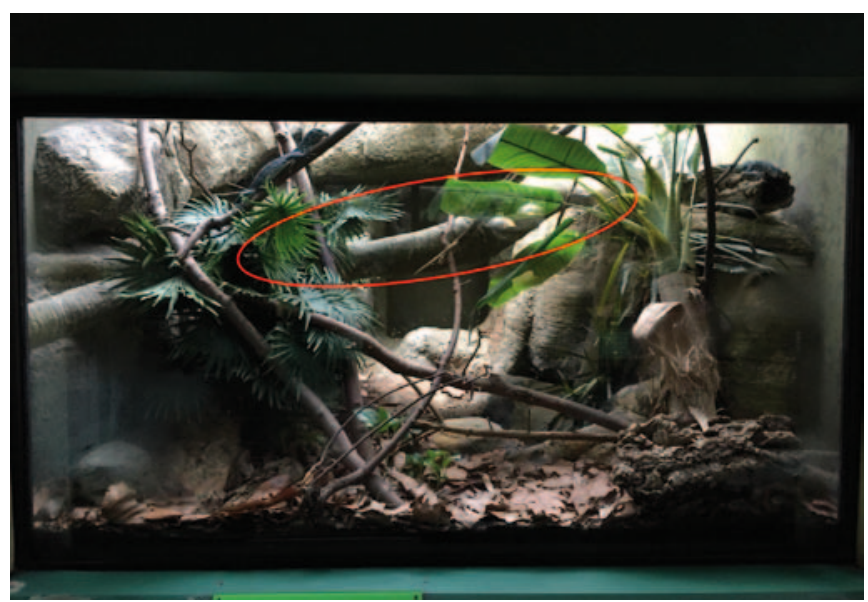

Figure 1. Photograph of the enclosure in which the study took place. Basking zone area is indicated by the red circle.

Heating arrays that allow the animals to heat up faster, to reach a given surface temperature (within appropriate limits), should be beneficial by mimicking more natural conditions. The most likely explanation for the observed difference in

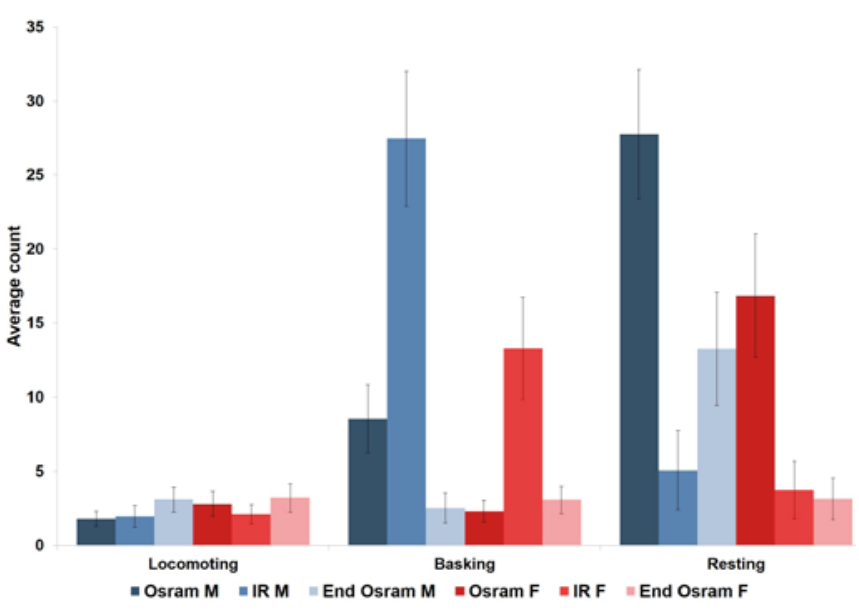

Figure 2. Average counts for each of the behaviours. Error bars show standard errors. Osram is the mercury vapour lamp and IR is the infrared deep heater. 'End Osram' is the return to mercury vapour lamp heating after the trial period with the infrared deep heater. $M$ and $\mathrm{F}$ correspond to male and female.

basking time between the heat sources is the difference in proportions of IR-A and IR-B emitted by them. Different wavelengths of radiation have different effects on the warming of an animal (Barolet et al., 2016). Skin is the primary surface that is exposed to radiation and as such absorbs and reflects high proportions of it (Porter, 1967).

Between $60-70 \%$ of incident sunlight is absorbed by the epidermis, compared to $10-20 \%$ for the underlying muscle (Porter, 1967). The epidermis is heated most intensely by IR-B radiation, provided by the IR lamps. Here, the inner heating of the deeper tissues occurs through conduction of heat from the skin into the deeper tissues. In contrast, the mercury vapour lamps produce IR-A and visible light that have higher penetrative abilities than IR-B (Barolet et al., 2016). Some of the IR-A radiation is transmitted through the skin and directly into the deeper subcutaneous tissues, giving more rapid bodily warming than IR-B.

Although there was an increase in the amount of time spent basking by the female lizard, we did not find this to be statistically significant. As the female was smaller than the male there might have been a risk of competitive exclusion from the basking zone (Žagar et al., 2015) but given that the basking zone was large enough to accommodate both monitors this seems unlikely. More likely was that being smaller the female heated up more quickly than the male.

Overall, our data show a clear difference in the effects of the two heating arrays used in the study. From the perspective of optimising animal husbandry, the relatively new IR-B emitter, although more energy efficient, is likely to be less effective than mercury-vapour lamps for providing basking sites for captive $V$. macraei and likely other similarly sized lizards. We did not compare the IR-B emitter with a ceramic heater, which produces IR-C wavelengths that penetrate even less effectively into epidermis. It is likely that the IR-B emitter might perform better than IR-C emitters for reptile heating, but this remains untested. Practical decisions need to be made when designing enclosures for captive reptiles. These decisions must take into account species-specific 
requirements and equipment costs. While the benefits of UV lighting in reptile husbandry are reasonably well known there is a surprising lack of information on IR heating. Future study should focus on IR heating arrays for the best benefit of captive stock.

\section{ACKNOWLEDGEMENTS}

We would like to thank Dr. Frances Baines for her advice and insight with the manuscript and Rick Hodges for his editorial assistance.

\section{REFERENCES}

Autumn, K. \& De Nardo, D.F. (1995). Behavioral thermoregulation increases growth rate in a nocturnal lizard. Journal of Herpetology: 157-162.

Baines, F., Chattell, J., Dale, J., Garrick, D., Gill, I., Goetz, M., Skelton, T. \& Swatman, M., (2016). How much UV-B does my reptile need? The UV-Tool, a guide to the selection of UV lighting for reptiles and amphibians in captivity. Journal of Zoo and Aquarium Research 4: 42-63.

Barolet, D., Christiaens, F. \& Hamblin, M.R. (2016). Infrared and skin: Friend or foe. Journal of Photochemistry and Photobiology B: Biology 155: 78-85.

Beaupre, S.J. \& Zaidan, F. (2012). Digestive performance in the timber rattlesnake (Crotalus horridus) with reference to temperature dependence and bioenergetic cost of growth. Journal of Herpetology 46: 637-643.

Fox, J. \& Weisberg, S. (2011). An $\{R\}$ Companion to Applied
Regression. Second Edition. Thousand Oaks CA: Sage. URL: http://socserv.socsci.mcmaster.ca/jfox/Books/Companion

Michaels, C.J., Downie, J.R. \& Campbell-Palmer, R. (2014). The importance of enrichment for advancing amphibian welfare and conservation goals. Amphibian Reptile Conservation 8: 7-23.

Porter, W.P. (1967). Solar radiation through the living body walls of vertebrates with emphasis on desert reptiles. Ecological Monographs 37: 273-296.

R Core Team (2018). R: A language and environment for statistical computing. R Foundation for Statistical Computing, Vienna, Austria. URL https://www.R-project. org/

Social Science Statistics. Friedman Test Calculator. (Accessed: 21 May 2019). Retrieved from: https://www. socscistatistics.com/tests/friedman/default.aspx?f bclid=IwAR0ixFw7Am6qfh10WpBFVAfL96KpNeGp_ vXjz8aSdLRBooelCuqu_1JkEHM

Žagar, A., Carretero, M.A., Osojnik, N., Sillero, N. \& Vrezec, A. (2015). A place in the sun: interspecific interference affects thermoregulation in coexisting lizards. Behavioral Ecology and Sociobiology 69: 1127-1137.

Ziegler, T., Strauch, M., Pes, T., Konas, J., Jirasek, T., Rütz, N., Oberreuter, J. \& Holst, S. (2009). First captive breeding of the blue tree monitor Varanus macraei Böhme \& Jacobs, 2001 at the PIzen and Cologne Zoos. Biawak 3: 122-133.

Accepted: 22 August 2019 